\title{
Managing Interdisciplinary Links in the Educa- tional Environment of Technical Colleges
}

\author{
Alsu Kamaleeva ${ }^{1}$, Natalya Nozdrina $^{2}$ and Suriya Gilmanshina ${ }^{3}$ \\ ${ }^{1}$ Institute of Pedagogy, Psychology and Social Problems, 12 Isaeva str., Kazan, 420039, Republic of Ta- \\ tarstan, the Russian Federation; \\ ${ }^{2}$ Bryansk State Technical University, 241035, Bryansk, Kharkiv str., 10-B; the Russian Federation; \\ ${ }^{3}$ Kazan Volga Federal University, Department of chemical education. The Kremlin str., 18, Kazan, Re- \\ public of Tatarstan, the Russian Federation
}

\begin{abstract}
The main methods of research are the analysis of scientific literature devoted to the problem of implementing interdisciplinary links of natural science, professional cycle disciplines, interdisciplinary courses in the institutions of secondary vocational education. To solve the integrated goal of implementing the requirements of the educational and professional standard of technical colleges we propose to use four types of interdisciplinary horizontal and vertical links, covering the subjects of natural science and general professional cycle, interdisciplinary courses, educational and industrial practice and professional standard requirements for education and training. It is proposed to distinguish four types of interdisciplinary links, aimed at solving the integrated goal of implementing the requirements of the educational and professional standard of technical colleges. In modern high-tech society there is a rapid dynamic growth of information on all branches of scientific knowledge, the emergence of new technologies and advanced forms and methods of work. These things make it difficult to identify the main and essential educational information, so the necessity to manage interdisciplinary links in the innovative educational environment of technical colleges is of primary consideration in developing modern professional Russian education.
\end{abstract}

\section{Introduction}

The necessity for a student's systemic worldview due to the constant implementation of interdisciplinary links has always been noted by scientists, starting with Y.A. Komenski. A great contribution to the development of interdisciplinary link problem was made by such scientists as A.A. Bobrov, I.D. Zvereva, A.F. Zubov, B.S. Elagina, V.N. Maksimova, A.V. Usova, V.N. Fedorova and others.

Implementing intersubject and interdisciplinary links in the process of teaching natural science and professional cycle subjects in the system of secondary and higher education is considered in the dissertation researches of S. N. Babina, V. E. Medvedev, V. A. Osnovina, S. A. Starchenko, N. S. Fayzullayeva, O. A. Yavoruka, A. R. Kamaleeva, F. Zannoni, J. D. Russell, M. D. Merrill, etc.[9, 11, 14, 15]. Heads of colleges, especially technical ones, are faced with the task of managing and regulating the process of implementing interdisciplinary links.

\section{Materials and methods}


Teachers of disciplines of natural science general educational cycle in technical colleges in their practical work solve the problems of implementing both interdisciplinary and intradisciplinary links. This is due to the necessity to identify general scientific laws and principles, to introduce generalized concepts that are successfully used in various scientific and technical disciplines.

Interdisciplinary links are classified for various reasons [3]. Mainly they are divided into groups according to time and information signs. Therefore, chronological and content-related interdisciplinary links are distinguished (Fig. 1) [2].

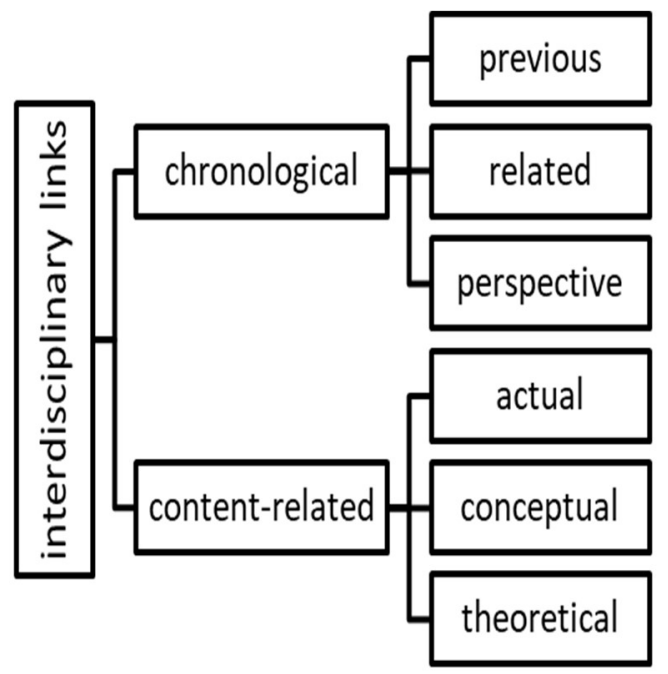

Fig. 1. Classification scheme of interdisciplinary links

Chronological interdisciplinary links are divided into perspective, related and previous in use.

Previous links are made with the material that has been studied in other disciplines earlier. For example, in the process of studying kinematics and statics in physics lessons, the link with the material previously studied in mathematics lessons (linear algebra, quadratic function, discriminant, etc.) is used [3].

Related links are made between concepts, laws, theories, simultaneously studied in related disciplines (for example, the concepts of the atom, valence, etc.).

Perspective links are such connections, when previously studied material in a subject is the basis for studying other disciplines. Thus, the concepts of "matter", "space", "time", first studied at the lessons of physics and chemistry, are summarized at social study lessons.

Content-related interdisciplinary links are divided into theoretical, conceptual, and actual based on the specific content of the studied educational material.

Theoretical links are made at the level of laws and theories, such as the molecular-kinetic theory of the structure of matter in physics and chemistry, classical mechanics and the laws of motion of bodies in physics and astronomy, etc.

Conceptual links are based on concepts. Thus, the concepts of "atom", "molecule", "ion", etc. are common for physics and chemistry, and for mathematics and physics "vector", "derivative", "integral", etc. are common.

Actual links are based on facts. For example, the fact of the matter division is studied in chemistry and physics, the movements of planetary systems are studied in astronomy and physics[6].

In recent years, much attention has been paid to general scientific methodological principles, such as the principle of conformity, complementarity, causality, symmetry at the level of 
inter-scientific generalizations. This fact became the basis for implementing interdisciplinary links at the level of inter-scientific generalizations. [4]. This allows you to use a scientifically based methodology to solve the problem of students' forming scientific thinking about the unity of the material world and the relationship of nature [6].

\section{Results}

To study the design of curricula for natural science and general professional disciplines in 2013, a didactic tool - a questionnaire was developed, which included 6 blocks reflecting the following positions on assessing design results. One of the blocks was devoted to studying the quality of interdisciplinary relation implementation (questions No.: 19, 20, 21 out of 36 questions). This questionnaire made it possible to assess the pedagogical situation of design and the state of teaching natural science and general professional disciplines in technical colleges in different regions of the Russian Federation [13].

Among $30 \%$ of surveyed teachers in natural science and general professional disciplines they note the importance of taking into account interdisciplinary links, especially when it comes to choosing methods and forms of education (38\%), as well as in the process of forming professional competencies (31\%) (Fig. 2).

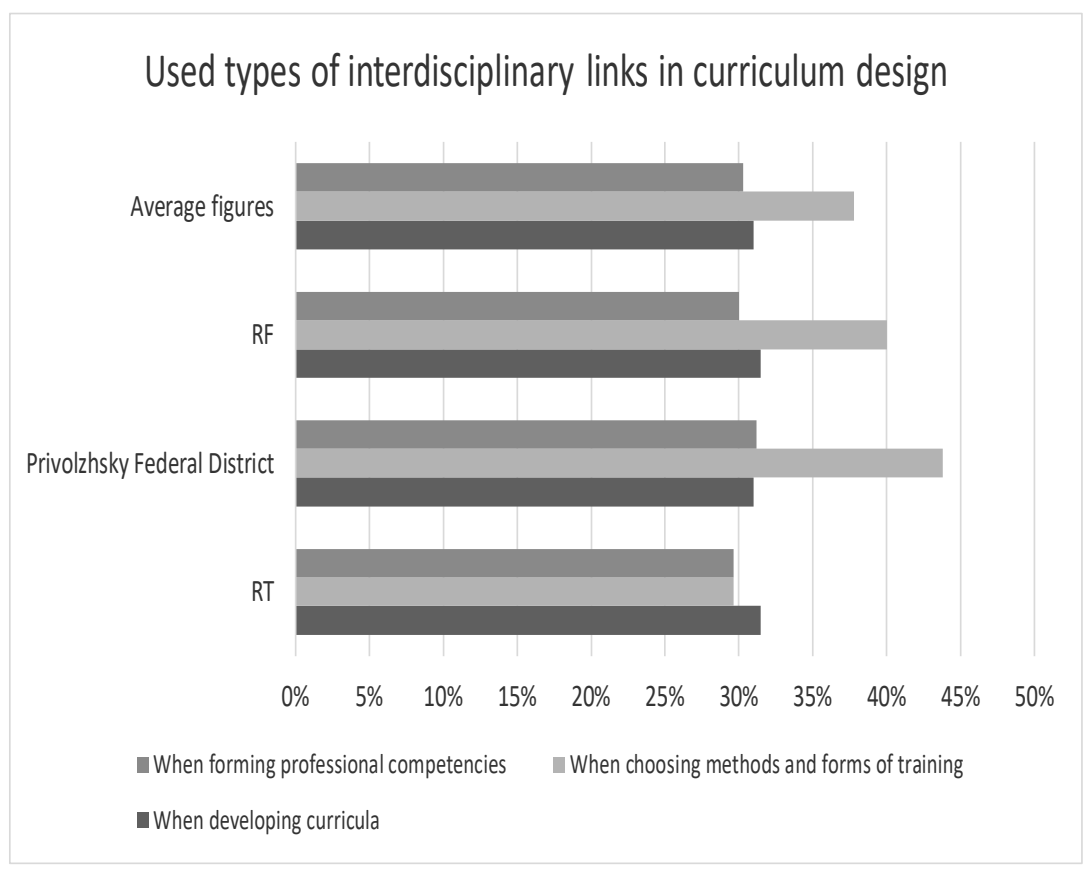

Fig. 2. Accounting for interdisciplinary links by technical college teachers (according to the results of the 2013 survey)

Teachers of technical colleges in the process of designing training courses equally use previous, related and subsequent (perspective) links [7].

A re-survey in the summer of 2017 was already conducted in the process of active integration of the Federal State Educational Standard 4 Secondary Vocational Education and Professional Standards.

Designing discipline curricula, as the survey showed, is focused on the interdisciplinary link consideration. Most actively they are implemented in choosing methods and forms of education $(91.12 \%)$, which corresponds to the unity of requirements for organizing certain meth- 
ods and forms of education in colleges, especially technical ones. Quite fully, they are used in forming general competencies, professional competencies and professional qualifications $(80.49 \%)$ [11]. This process meets the requirements of educational and professional standards. Particular characteristics of each discipline affect the reduction of using interdisciplinary links in designing training courses (68.29\%) [9] (Fig. 3).

\section{Consideration of interdisciplinary links in curriculum design}
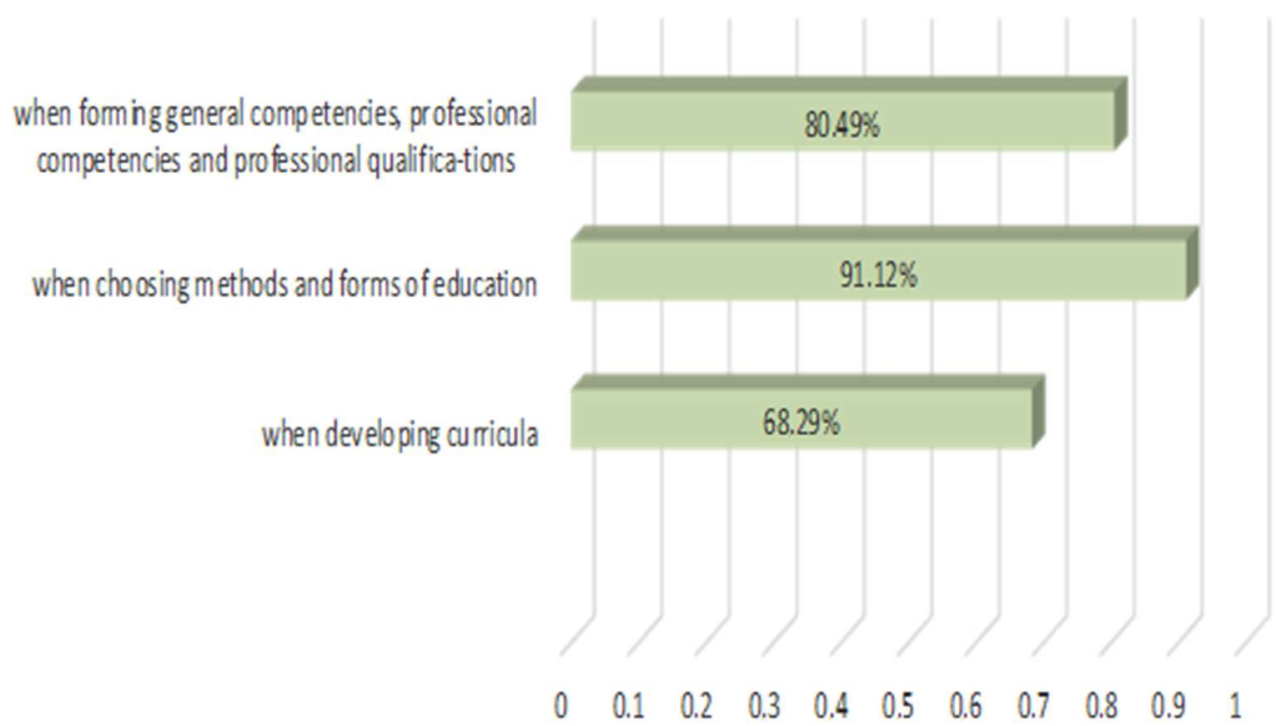

Fig. 3. Consideration of interdisciplinary links by technical college teachers (according to the results of the 2017 survey)

The survey results show that using various types of chronological interdisciplinary links has become even more relevant for teachers (see Fig. 5). Moreover, the ratio of these links has changed and perspective and related links have become more significant for technical college teachers (Fig. 4). 


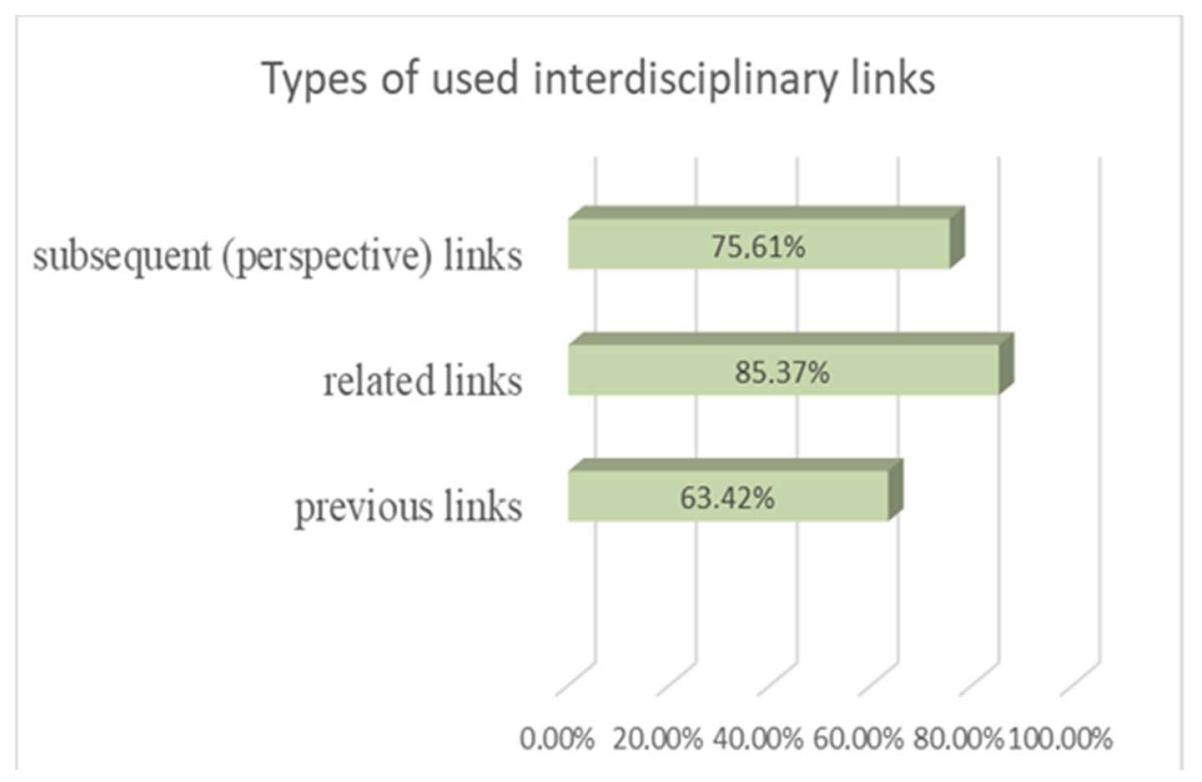

Fig. 4. The ratio of using chronological interdisciplinary links by technical college teachers (according to the results of the 2017 survey)

Introducing new technologies, methods and forms of education in accordance with the introduced educational and professional standards causes some difficulties in designing training courses, taking into account the implementation of interdisciplinary links of various types. They are most actively implemented while studying the disciplines of the professional cycle $(97.30 \%)$, then the disciplines of the mathematical and general natural cycle $(78.10 \%)$. The necessity to have links with various types of practice (educational and industrial) is estimated at $68.20 \%$, and with the disciplines of the general humanitarian and socio-economic cycle at $51.20 \%[14]$.

\section{Conclusion}

Thus, it can be stated that the necessity to integrate educational and professional standards dictates the need to strengthen interdisciplinary links with the special disciplines that are the part of the interdisciplinary cources. It is these disciplines, along with educational and industrial practice, that are closest in their content and purpose to the professional standard. We agree with the opinion that "since competence in pedagogy is viewed as an integrative characteristic of a specialist's personality, interdisciplinary link is the mechanism by means of which the direction of the training content for all disciplines of the basic educational program for forming general and professional competencies defined by the Federal State Educational Standard can be implemented" [15].

Most scientists, speaking about the classification of interdisciplinary links by content, distinguish four interdependent relations:

1) by commonality of laws, concepts, theories;

2) by commonality of scientific facts relating to the same object of study;

3) by commonality of using the scientific method;

4) by commonality of mental activity methods $[10,11]$.

At the same time, there is a necessity for orientation of all interdisciplinary links to solving the main didactic tasks assigned to any institution of secondary vocational education by both educational and professional standards [12]. 
Based upon the idea of the researchers Bezrukova N. P., Agafonova I. P., and B. Goldschmidt, M. Goldschmidt, C. M. Ashmore and S. G. Prits [1, 6] highlighting the interdisciplinary links of three types, we propose to distinguish four types of interdisciplinary links, aimed at solving the integrated goal of implementing the requirements of the educational and professional standards of technical colleges:

- Type 1 - based on interdisciplinary links of the training content providing the connection of natural science cycle disciplines with general educational disciplines;

- Type 2 - based on interdisciplinary links of the content of training general professional disciplines;

- Type 3 - based on interdisciplinary links of the content of training interdisciplinary courses and educational and industrial practice;

- Type 4 - based on the professional standard requirements for education and training.

\section{Consequences}

1. In modern professional education, interdisciplinary links are considered as a form of the universal principle of consistency.

2. There are chronological and content-related interdisciplinary links:

- chronological interdisciplinary links are classified into the previous, related and perspective on a temporary basis;

- content-related interdisciplinary links are classified into actual, conceptual and theoretical. 3. An analysis of an experimental study of designing curricula for natural science and general professional disciplines in technical colleges has revealed certain difficulties for teachers in the rational and, most importantly, in the optimal use of various types of interdisciplinary links in designing training courses. If the results of the 2013 survey show that when designing curricula, all three types of interdisciplinary links were equally used: previous (preliminary), related, perspective, then the results of the 2017 survey speak for the fact that teachers, in terms of integrating educational and professional standards highlight the necessity to realize a close interdisciplinary link with the professional cycle disciplines $(97.30 \%)$, with the disciplines of the mathematical and natural science cycle $(78.10 \%)$; with educational and industrial practice $(68.20 \%)$, with disciplines of the general humanitarian and socio-economic cycle $(51.20 \%)$.

4. In modern high-tech society, there is a rapid dynamic growth of information in all branches of scientific knowledge, the emergence of new technologies and progressive forms and methods of work, which makes it difficult to identify the main and essential educational information in the learning process in conjunction with other disciplines. This is especially relevant in choosing the content for teachers of the general professional cycle disciplines and interdisciplinary courses due to the instability of the subject itself, which varies in accordance with the evolving techniques and technology.

5. To successfully manage the process of rational and optimal implementation of interdisciplinary links in technical colleges, we propose to distinguish four types of interdisciplinary links (aimed at solving the integrated goal of meeting the requirements of the educational and professional standards of technical colleges (forming the students' general competencies, professional competencies and professional qualifications):

- Type 1 - based on interdisciplinary links of the training content providing the connection of natural science cycle disciplines with general educational disciplines (interdisciplinary links of the $1^{\text {st }}$ type);

- Type 2 - based on interdisciplinary links of the content of training general professional disciplines (interdisciplinary links of the $2^{\mathrm{d}}$ type);

- Type 3 - based on interdisciplinary links of the content of training interdisciplinary courses and educational and industrial practice (interdisciplinary links of the $3^{\mathrm{d}}$ type); 
- Type 4 - based on the professional standard requirements for education and training (type interdisciplinary links of the $4^{\text {th }}$ type).

\section{References}

1. C.M. Ashmore, S.G. Prits, Program for acquiring competence in entrepreneurship: Instructor Guide. (Columbus: Ohio State Univ. Press 1983).

2. L. Bertalanffy, General system theory: Foundations, development, applications (N-Y: Braziler, 1969)

3. S. Bickford, Computer Pictures, 2, 45 (1988)

4. E. De Bono, Six thinking hats (Boston: Little Brown Co, 1985)

5. E. Feigenbaum, Machine Intelligence, 6, 181 (1971)

6. B. Goldschmidt, M. Goldschmidt, Higher Education, 2, 15 (1972)

7. J. P. Guilford, The nature of human intelligence (N.Y.: David McKey Co, 1967)

8. M. Lange, Geometry in modules. Teacher's manual (London: Addison Wesley P.C, 1986)

9. M.D. Merrill, Instructional Design: Readings (Inglewood Cliffs, NJ: Prentice-Hall, 1971)

10. Modularization and the new curricular (London : FESC Report, 1986)

11. J.D. Russell, Modular instruction. A guide to the design, selection, utilization and evaluation of modular materials (Minneapolis, MN: Burgess Publishing 1974)

12. B. Schults, Computer pictures, 1, 11 (1988)

13. M. Harring, O. Bohm-Kasper, C. Rohlfs, Palentien Chr. Peers als Bildungs- und Sozialisationsinstanzen - eine Einfuhrung in die Thematik. (VS-Verlag, Wiesbaden, 2010)

14. A. R. Kamaleeva, International Journal of Applied and Fundamental Research, 2, 5 (2015)

15. F. Zannoni, International Journal of Cross-Cultural Studies and Environmental Communication, 4:2, 87 (2017)

16. F. Zannoni, La città divisa. Conflittualità, confini, prove di comunità (The divided city. Conflicts, borders, community practices 2015 ) 